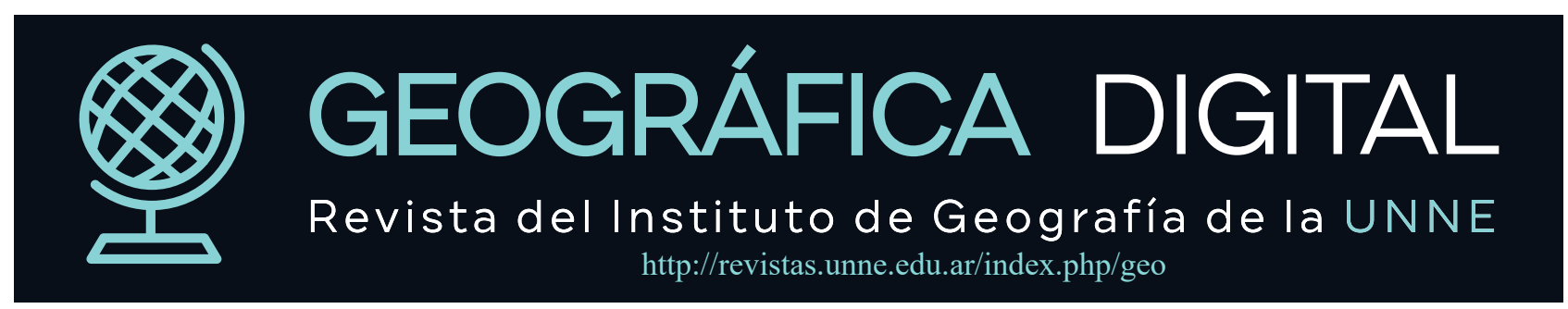

Revista Geográfica Digital, 2020, Vol. 17, No 34, 2-17 pp., E-ISSN: 1668-5180: DOI: http://dx.doi.org/10.30972/geo.17344444

\title{
Efectos de la variabilidad climática sobre las coberturas del suelo de distintas cuencas hidrográficas de Argentina
}

\section{Climate variability effects on land covers in different hydrographic basins located in Argentina}

\section{Ferrelli, Federico}

Instituto Argentino de Oceanografía (IADO), Universidad Nacional del Sur (UNS)-CONICET, Bahía Blanca, Argentina. Complejo CCT CONICET Bahía Blanca. - Universidad Nacional del Sur, Departamento de Geografía y Turismo, Bahía Blanca, Argentina. fferrelli@criba.edu.ar

Palabras claves: Eventos secos y húmedos Coberturas del suelo Argentina
Keywords:

Dry and wet events

Land covers

Argentina.

\section{R E S U M E N}

Las cuencas hidrográficas son espacios que responden a los cambios ambientales que ocurren en el paisaje. La variabilidad climática genera impactos sobre sus coberturas del suelo. En este contexto, el objetivo de este estudio fue analizar la periodicidad, frecuencia, duración e intensidad de eventos secos y húmedos que se presentaron en seis cuencas hidrográficas localizadas en distintas regiones de Argentina y sus efectos sobre las coberturas del suelo. Para ello, se utilizó el Î́ndice Estandarizado de Precipitación y Evapotranspiración para estudiar los eventos secos y húmedos ocurridos durante el período 1951-2019. Una vez identificados, se analizaron los efectos sobre las coberturas del suelo para el período 1992-2018, dado que coincide con la disponibilidad de los productos libres y gratuitos proporcionados por la Agencia Espacial Europea. Los resultados demostraron que los eventos extremos de precipitación se presentaron en simultáneo en la mayor parte de las cuencas, exceptuando aquellas localizadas en climas áridos y fríos. La ocurrencia de eventos secos y húmedos fue mayor en los climas subtropicales y templados. Se destaca el clima mediterráneo dado que no presentó eventos húmedos luego de 1985 y no tuvo eventos secos durante el período 1954-1984. Los efectos de la variación de la precipitación y la evapotranspiración se identificaron en las coberturas del suelo. En algunos casos, las variaciones ocurrieron en las de menor superficie. Los resultados obtenidos conforman una base de datos esenciales para guiar políticas destinadas a mejorar la calidad de vida de la población y del ambiente con vistas a la implementación de un desarrollo sustentable.

\section{A B S T R A C T}

The hydrographic basins respond to environmental changes that occur in the landscape. The climate variability has impacts on the land covers. In this context, the aim of this study was to analyze the periodicity, frequency, and duration of dry and wet events in six basins located in different climate regions of Argentina, and their effects on the land cover changes. To do so, the Standardized Precipitation and Evapotranspiration Index was calculated to identify wet and dry events during the period 1950-2019. Moreover, there was analyzed the land cover changes during wet and dry events. The products from the European Satellite Agency were evaluated for the period 1992-2018. Results demonstrated that the extreme precipitation events were presented simultaneously in most of the basins, except in those located in arid and cold climates. The Mediterranean basin did not show wets events after 1985, and during the period 1954-1984 presents a lack of dry ones. The occurrence of wet and dry events was higher in subtropical and temperate basins. The rainfall variability was reflected in the land cover for all basins. In some cases, these variations were registered in the land cover with less expansion. Results are an essential database to guide policies for improving life quality associate with sustainable development. 


\section{Introducción}

El análisis de los eventos secos y húmedos y sus efectos sobre las coberturas del suelo son de gran relevancia para preservar la calidad de vida de la población y el ambiente (Lehner et al., 2006). El estudio del clima es un factor clave para determinar las diferentes características y distribución de los recursos hídricos. En este contexto, la ocurrencia de eventos secos y húmedos definen ciclos estacionales, así como también variaciones interanuales que afectan directamente a las coberturas del suelo (Aliaga et al., 2016). La variabilidad climática impacta en las zonas sembradas, la hacienda, las viviendas y las ciudades. Esto genera consecuencias en la economía regional, a partir del impacto socioeconómico que causan (Taboada et al., 2012). Entre los efectos sobre la población se destacan la accesibilidad al agua potable, la provisión de energía, el acceso a plantas medicinales, desplazamiento y desaparición de animales y recursos pesqueros, pérdidas de cosechas, etc. (Houghton, 1993; Ferrelli, 2017; Brendel et al., 2017).

En este contexto, adquieren relevancia las cuencas hidrográficas dado que son integradores de cambios medioambientales que ocurren en el paisaje terrestre. Además de proveer agua potable, ser espacios donde se favorece la recreación y ser utilizados en industria, proveen servicios ecosistémicos y recursos naturales (Williamson et al., 2009). Los lagos brindan información valiosa acerca de los patrones y mecanismos de respuesta de los sistemas acuáticos al cambio climático (Adrian et al., 2009).

Es en este contexto que la teledetección surge como una herramienta de monitoreo ambiental. Su importancia recae en que permite observar estos espacios de forma periódica (dependiendo de su resolución temporal) (Nosetto et al., 2005; Gordon et al., 2008). La reflectividad de la superficie terrestre es un indicador de diferentes características y del estado de los recursos naturales, siendo el agua, los cultivos y los pastizales los más variables en el tiempo (Ferrelli et al., 2015).

Está demostrado que en la mayor parte del territorio de Argentina es propenso a sufrir los efectos de la variabilidad climática debido a la ocurrencia de distintos fenómenos que modifican la circulación atmosférica a escala regional (Aliaga et al., 2016; Brendel et al., 2017; Ferrelli et al., 2019). Estas fluctuaciones favorecen la generación de cambios espaciotemporales en las coberturas del suelo, impactando así sobre la sociedad y las actividades que ella desarrolla (Brendel et al., 2019). Por este motivo, en este trabajo se propuso realizar un estudio de los efectos de la variabilidad climática sobre las coberturas del suelo a escala nacional, tomando como unidad de análisis seis cuencas hidrográficas. En sentido norte-sur se consideraron:

- Cuencas de la Puna: localizadas en el noroeste del país, en las provincias de Catamarca, Salta y Jujuy. Corresponden al conjunto de cuencas endorreicas que tienen una superficie de 87.136 $\mathrm{km}^{2}$. Según la clasificación climática de Köppen, Köppen-Geiger y sus actualizaciones realizadas por Beck et al. (2018), esta cuenca se localiza dentro de las franjas climáticas áridas y frías. En ella, la temperatura media anual no supera los $18{ }^{\circ} \mathrm{C}$ y el régimen de precipitaciones es seco intermedio, es decir, que se caracteriza por presentar una oscilación entre árido y semi-árido (Köppen, 1918; Köppen y Geiger, 1936; Beck et al., 2018) (Figura 1 (1)).

- Cuenca del Río Aguapey: se localiza en el noreste del país, en la provincia de Corrientes y tiene una extensión de $8.106 \mathrm{~km}^{2}$. Su clima es Subtropical húmedo, con un régimen térmico en donde la temperatura media anual ronda los $22{ }^{\circ} \mathrm{C}$ y sus precipitaciones son abundantes y se concentran a lo largo de todo el año (Köppen, 1918; Köppen y Geiger, 1936; Beck et al., 2018) (Figura $1(2)$ ).

- Cuenca del Río Mendoza. Se localiza en la región de Cuyo, al oeste de Argentina. Se emplaza al norte de la provincia de Mendoza y tiene una superficie de $18.484 \mathrm{~km}^{2}$. Se ubica dentro de la franja de los climas mediterráneos, donde la temperatura media anual ronda los $22{ }^{\circ} \mathrm{C}$ y los veranos son cálidos. Las precipitaciones tienen una marcada estacionalidad (Köppen, 1918; Köppen y Geiger, 1936; Beck et al., 2018) (Figura 1 (3)).

- Cuencas de desagüe al Río de La Plata. Corresponde a un conjunto de cuentas hidrográficas localizadas en el noreste de la provincia de Buenos Aires. Su superficie es de $11.531 \mathrm{~km}^{2}$. Se emplaza dentro de los climas Subtropicales húmedos, al igual que la cuenca del Río Aguapey, pero estudios a escala regional demostraron que su clima es templado húmedo, con presencia de estacionalidad tanto térmica como pluviométrica (Aliaga et al., 2017). (Figura 1 (4)).

- Cuenca del Río Chubut. Se localiza al sur del país, en la Patagonia. Particularmente se extiende sobre las provincias de Río Negro y Chubut con un área de $52.235 \mathrm{~km}^{2}$. Su clima es Árido y frío determinado por su localización. Sus características son similares a las cuencas de la Puna (Köppen, 1918; Köppen y Geiger, 1936; Beck et al., 2018) (Figura 1 (5)). 
- Cuenca del Río Santa Cruz. Se localiza en la Patagonia, en la provincia de Santa Cruz. Tiene una superficie de $29.686 \mathrm{~km}^{2}$. Al igual que en el caso anterior, se localiza sobre las franjas de los climas Áridos fríos (Köppen, 1918; Köppen y Geiger, 1936; Beck et al., 2018) (Figura 1 (6)).

Figura 1. Localización del área de estudio.
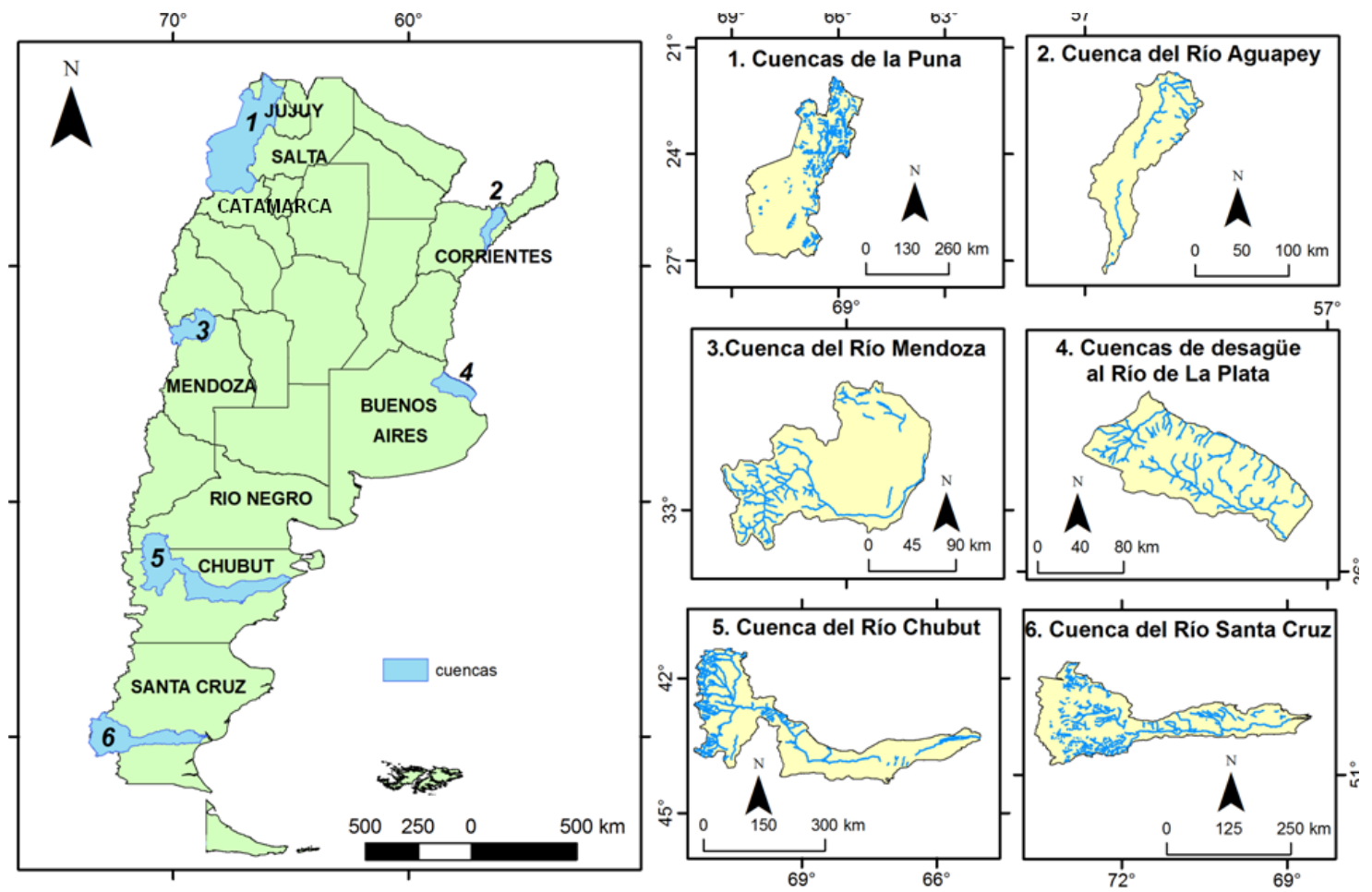

Fuente: elaboración propia, Ferrelli (2020).

Debido a los efectos que la sucesión de eventos secos y húmedos tienen las actividades económicas que realiza la sociedad y sobre los recursos naturales, el objetivo de este trabajo fue analizar la periodicidad, frecuencia, duración e intensidad de eventos secos y húmedos que se presentaron en las seis cuencas localizadas en Argentina y sus efectos sobre las coberturas del suelo. Este estudio adquiere importancia debido a que las investigaciones a escala nacional son escasas en lo que respecta a una investigación integral y comparativa de las cuencas y los reservorios de agua. En algunos territorios todavía se desconoce la variación natural del clima y los efectos de las variaciones de las coberturas del suelo, considerando que las cuencas y los reservorios de agua son una fuente esencial de servicios ecosistémicos, recursos naturales, espacios donde se emplazan gran número de actividades económicas y además, son ambientes en donde se desarrollan poblaciones importantes en todos los niveles tróficos.

\section{Materiales y métodos}

En este apartado se describieron los métodos aplicados para el análisis de los períodos secos, húmedos y normales y sus efectos sobre las coberturas del suelo en seis cuencas hidrográficas localizadas en distintas zonas climáticas de Argentina. En una primera instancia, se evaluaron los eventos secos, húmedos y normales a partir del estudio de series del Îndice Estandarizado de Precipitación y Evapotranspiración (SPEI). Con este análisis, se determinaron la frecuencia, intensidad, duración y periodicidad de los eventos. Posteriormente, con esta información, se analizaron los productos satelitales provistos por la Agencia Espacial Europea, con el objetivo de analizar las variaciones en las coberturas del suelo. El período de disponibilidad de los mismos fue 1992-2018, por lo que se consideraron los eventos ocurridos durante ese período. Finalmente, con análisis estadísticos de correlación y determinación, se establecieron las relaciones existentes entre las ocurrencia de los eventos pluviométricos y las variaciones en las coberturas del suelo en cada cuenca (Figura 2). 
Figura 2. Esquema metodológico aplicado en este estudio.

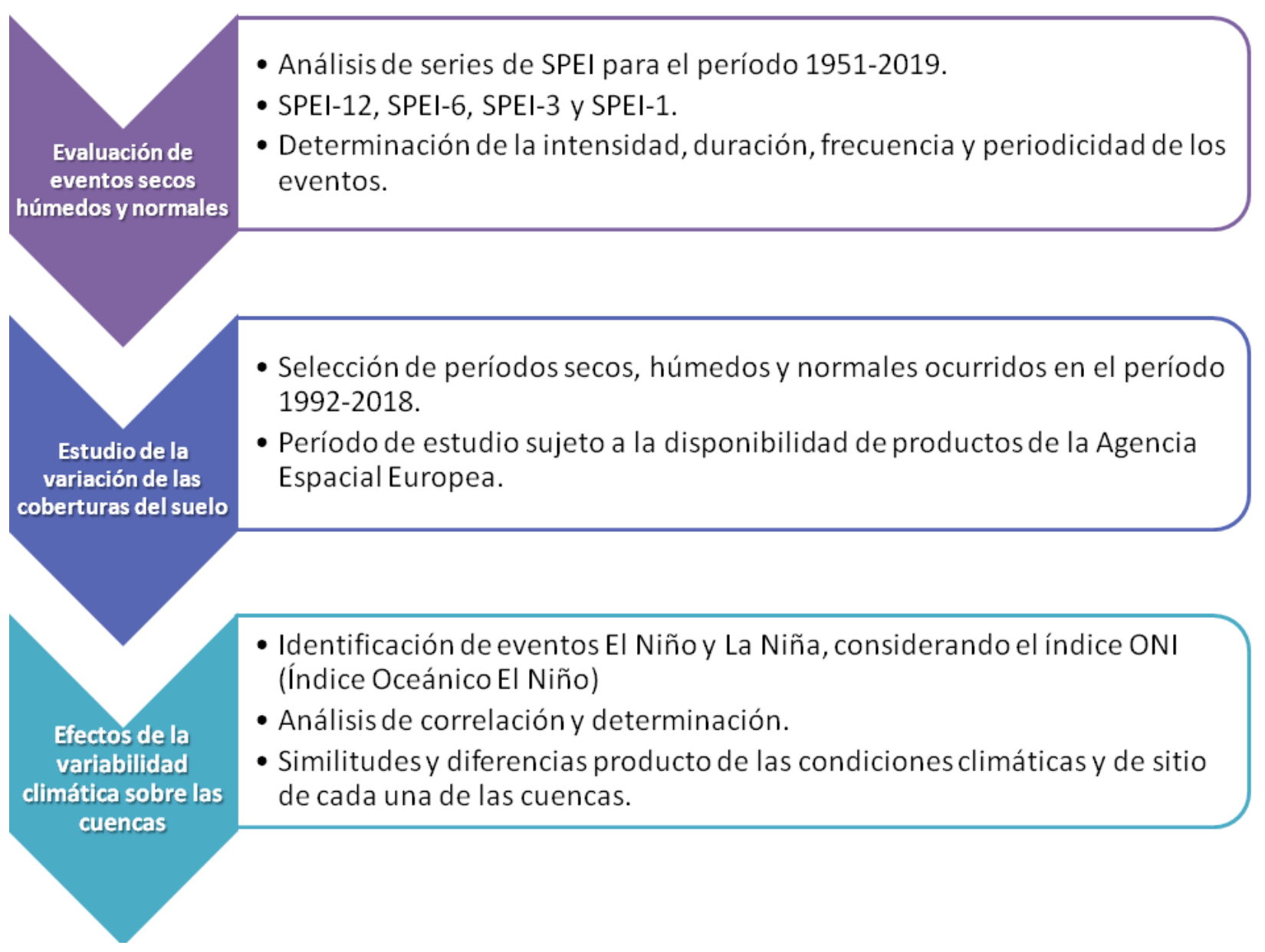

Fuente: elaboración propia, Ferrelli (2020).

\subsection{Evaluación de los eventos secos, húmedos y normales}

Se analizaron los eventos secos y húmedos a partir de la aplicación del Índice Estandarizado de Precipitación y Evapotranspiración (SPEI, Vicente-Serrano et al., 2010). Las series de datos fueron obtenidas del sitio web http://sac.csic.es/spei/home.html para el período 1951-2019 con una escala espacial de $0,5^{\circ}$ de longitud y latitud. Para cada una de las cuencas hidrográficas estudiadas, se descargaron las grillas correspondientes a toda su extensión y se realizó un promedio entre ellas para representar lo ocurrido a escala regional. Este índice considera la precipitación acumulada y la evapotranspiración potencial, por lo que es un buen indicador de los efectos de los períodos secos y húmedos sobre las coberturas del suelo (Bohn et al., 2016; Ferrelli, 2017).

Tabla 1. Categorías del Îndice Estandarizado de Precipitación y Evapotranspiración (SPEI).

\begin{tabular}{|c|c|}
\hline Valor de SPEI & Clasificación \\
\hline$>2$ & Extremadamente húmedo \\
\hline 1,5 a 1,99 & Muy húmedo \\
\hline 0,51 a 1,49 & Moderadamente húmedo \\
\hline$-0,5$ a 0,5 & Normal \\
\hline$-0,51$ a $-1,49$ & Moderadamente seco \\
\hline$-1,5$ a $-1,99$ & Extremadamente seco \\
\hline$<-2$ & \\
\hline
\end{tabular}

Fuente: Modificado de Vicente-Serrano et al., 2010.

El SPEI se aplicó considerando cuatro escalas temporales: mensual (SPEI-1), estacional (SPEI-3), semestral (SPEI-6) y anual (SPEI-12). De esta manera, se caracterizaron los eventos anuales siguiendo los 
criterios de la Tabla 1. Los valores de este índice oscilan entre -3 y 3 lo que permite establecer un criterio de clasificación de los eventos secos y húmedos, considerando su intensidad. El SPEI ha sido aplicado con éxito en otros estudios realizados en Argentina (Brendel et al., 2017; Bohn et al., 2016; Ferrelli, 2017).

A partir del conocimiento de la ocurrencia de los eventos secos y húmedos en distintas cuencas de Argentina, se procedió a caracterizar la variabilidad de estos a partir del estudio de la intensidad, duración y periodicidad. La primera de ellas hace referencia al valor medio que tienen los eventos secos y húmedos, la segunda se refiere a la cantidad media de meses que duran los eventos y la última corresponde a la cantidad de años que transcurren entre la ocurrencia de un evento y la recurrencia del otro (Aliaga et al., 2017).

\subsection{Análisis de las coberturas del suelo}

Una vez establecido el estudio de la variación de los eventos secos, húmedos y normales, se procedió a estudiar sus efectos sobre las coberturas del suelo. Para ello, se identificaron los eventos secos y húmedos más intensos y uno normal ocurridos durante 1992-2018. Posteriormente, se confeccionaron documentos cartográficos que identificaron las variaciones de las coberturas entre estos tres eventos.

En este análisis, se consideró este período de estudio debido a que las coberturas del suelo se evaluaron mediante la base de datos mundial provista por la Agencia Espacial Europea (ESA - Climate Change Initiative - www.esa-landcover-cci.org) (ESA, 2017). La misma corresponde a una base de datos realizada a partir del procesamiento de imágenes satelitales obtenidas por distintos satélites. Su resolución espacial es de 300 metros y se encuentra validado a nivel mundial. La clasificación de las coberturas del suelo fue realizada a escala mundial, por lo que sus definiciones han sido readaptadas, considerando las características de las cuencas de Argentina estudiadas en este trabajo. Esta información fue analizada con los Software ENVI y ArcGIS 10.1 con el objetivo de recortarla y obtener el área de cada cobertura. Posteriormente, se calcularon las superficies de las coberturas del suelo en cada una de las cuencas y se analizó su variación espacial.

Finalmente, se estudiaron las variaciones de las coberturas del suelo en relación a los resultados del SPEI-12 para el período 1992-2018 con un análisis de correlación, considerando el coeficiente de determinación (R2), los coeficientes de correlación de Pearson (P) y Spearman (S) y la Concordancia (C). Con estos resultados, se pudo establecer el efecto que la sucesión de eventos secos, húmedos y normales tiene sobre las coberturas del suelo de distintas cuencas hidrográficas de Argentina.

\section{Resultados}

En los siguientes apartados se presentaron los resultados de la variabilidad climática analizada a partir del índice SPEI para las seis cuencas hidrográficas. Posteriormente, se realizó un análisis de los efectos de eventos secos y húmedos sobre las coberturas del suelo.

\subsection{Análisis de los eventos pluviométricos}

Las cuencas hidrográficas de la Puna tuvieron la particularidad de no manifestar la existencia de eventos extremos. Todos los eventos analizados durante el período 1951-2019 fueron Secos, Húmedos y Normales, según la clasificación presentada en la tabla 1. La particularidad es que se presentaron un mayor número de eventos secos que húmedos. A partir de la década del 2000, los eventos tienden a ser Normales y Secos, mientras que antes de esta fecha, se evidenció una mayor fluctuación de eventos húmedos, secos y normales (Figura 3).

Las cuencas del Río Aguapey y las de desagüe al Río de La Plata tuvieron un comportamiento similar. Si bien en los casos extremos, la primera tuvo mayor cantidad de eventos extremos húmedos, y la segunda contabilizó mayor cantidad de extremos secos. Ambas presentaron similar número de eventos Normales, seguido de los Secos y los Húmedos. Su distribución interanual se caracterizó por ser más variable que el resto de las cuencas, identificando una mayor sucesión de ciclos secos y normales que el resto de las cuencas (Figura 3).

Un caso particular se observó en la cuenca del Río Mendoza. Si bien se presentaron todos los tipos de eventos analizados, durante 1985 hasta 2019, no se observó la presencia de eventos húmedos de ninguna intensidad. Por otro lado, durante el período 1954-1984 predominaron sólo los eventos húmedos (Figura 3). 
Por otro lado, las cuencas del Río Chubut y Santa Cruz tuvieron comportamientos diferentes a pesar de emplazarse dentro de la misma franja climática. En la primera se contabilizaron todos los tipos de eventos, mientras que en la segunda no se registraron eventos extremos. A pesar de ello, en ambas se identificó una gran variación pluviométrica interanual (Figura 3).

Los eventos húmedos tuvieron mayor duración en la cuenca del Río Santa Cruz (8,6 meses) y menor en la cuenca del Río Aguapey (3,5 meses). Sin embargo, se identificaron un mayor número de eventos húmedos de mayor intensidad en las cuencas localizadas en los climas subtropicales (Aguapey = 22 eventos) y en las de clima templado pampeano (desagüe al Río de La Plata = 17) (Figura 4). Los mismos fueron más periódicos en la cuenca del Río Aguapey (3,2 años), seguidos por la de desagüe al Río de La Plata (4,3 años), Chubut (4,8 años), Santa Cruz (5,3 años), Puna (6,5 años) y Mendoza (7,2 años).

Figura 3. Número de eventos secos y húmedos y distribución del SPEI en cada una de las cuencas.
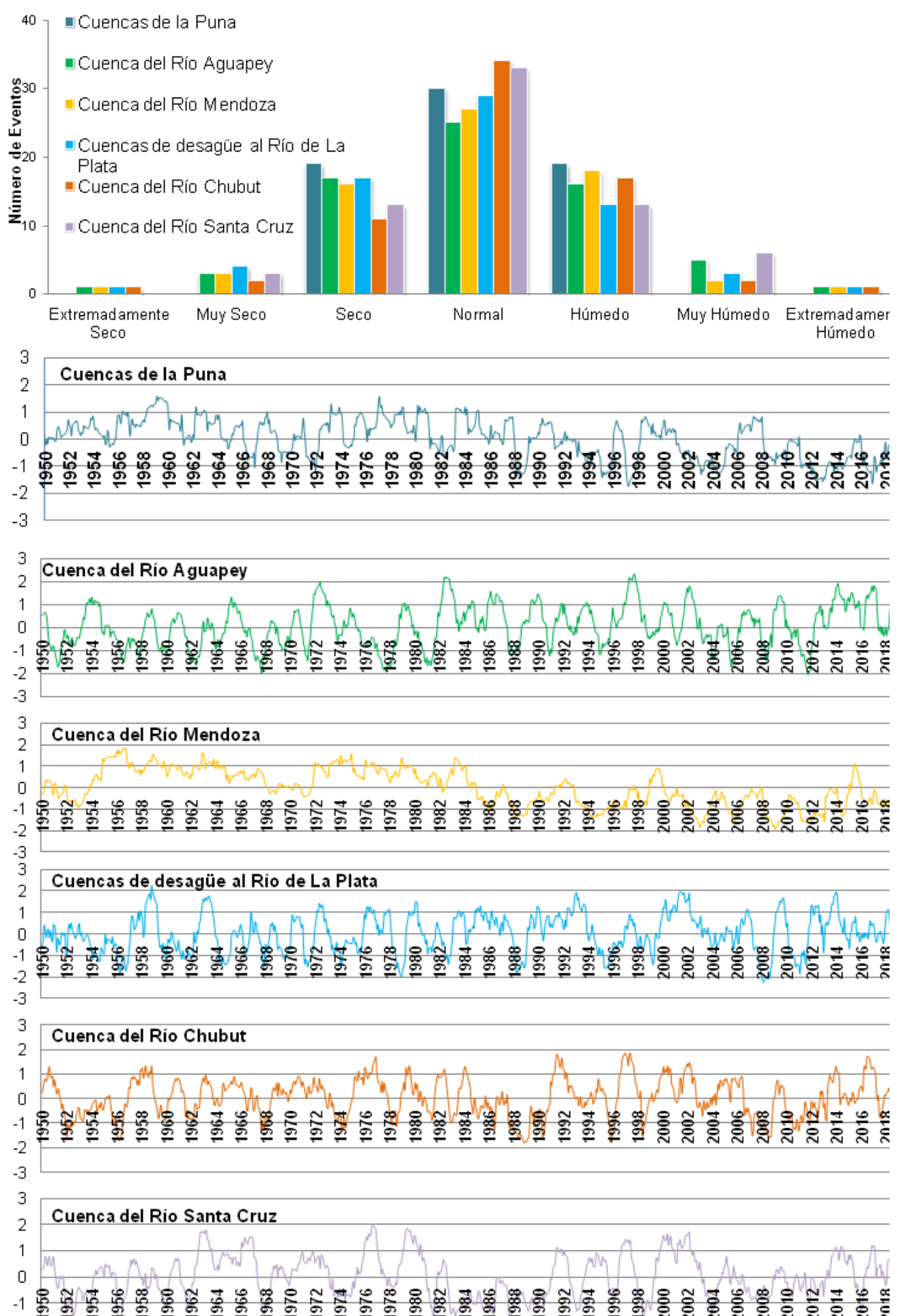

Fuente: elaboración propia, Ferrelli (2020). 
Los eventos secos presentaron una mayor duración en la cuenca del Río Mendoza (7,1 meses), seguidos por la del Río Santa Cruz (6,2 meses) y Chubut (5,8 meses). Cabe mencionar que en el caso de la Puna los eventos tanto secos como húmedos tuvieron similar duración con un total de 3,9 y 4,2, respectivamente. Además, cabe destacar que la cuenca del Río Aguapey tuvo los eventos de menor duración de todos los casos analizados (Figura 4). El análisis de la periodicidad de los eventos húmedos demostró que los mismos son mayores en la cuenca del Río Aguapey (3,5 años), seguidos por la de desagüe al Río de La Plata (4,5 años), Puna (4,9 años), Chubut (5,1 años), Santa Cruz( 5,3 años) y Mendoza (8 años).

Por otro lado, los eventos húmedos fueron más intensos en la cuenca de desagüe al Río de La Plata (SPEI $=1,23)$, seguidos por la del Río Aguapey $(1,15)$ y la del Río Mendoza (1,12). Por otro lado, los eventos secos más intensos se registraron en la cuenca del Río Aguapey (SPEI = -1,15), seguida por la del Río Santa Cruz (SPEI = -1,12) (Figura 4).

Figura 4. Duración (1) e intensidad (2) de los eventos secos y húmedos en las cuencas hidrográficas estudiadas.

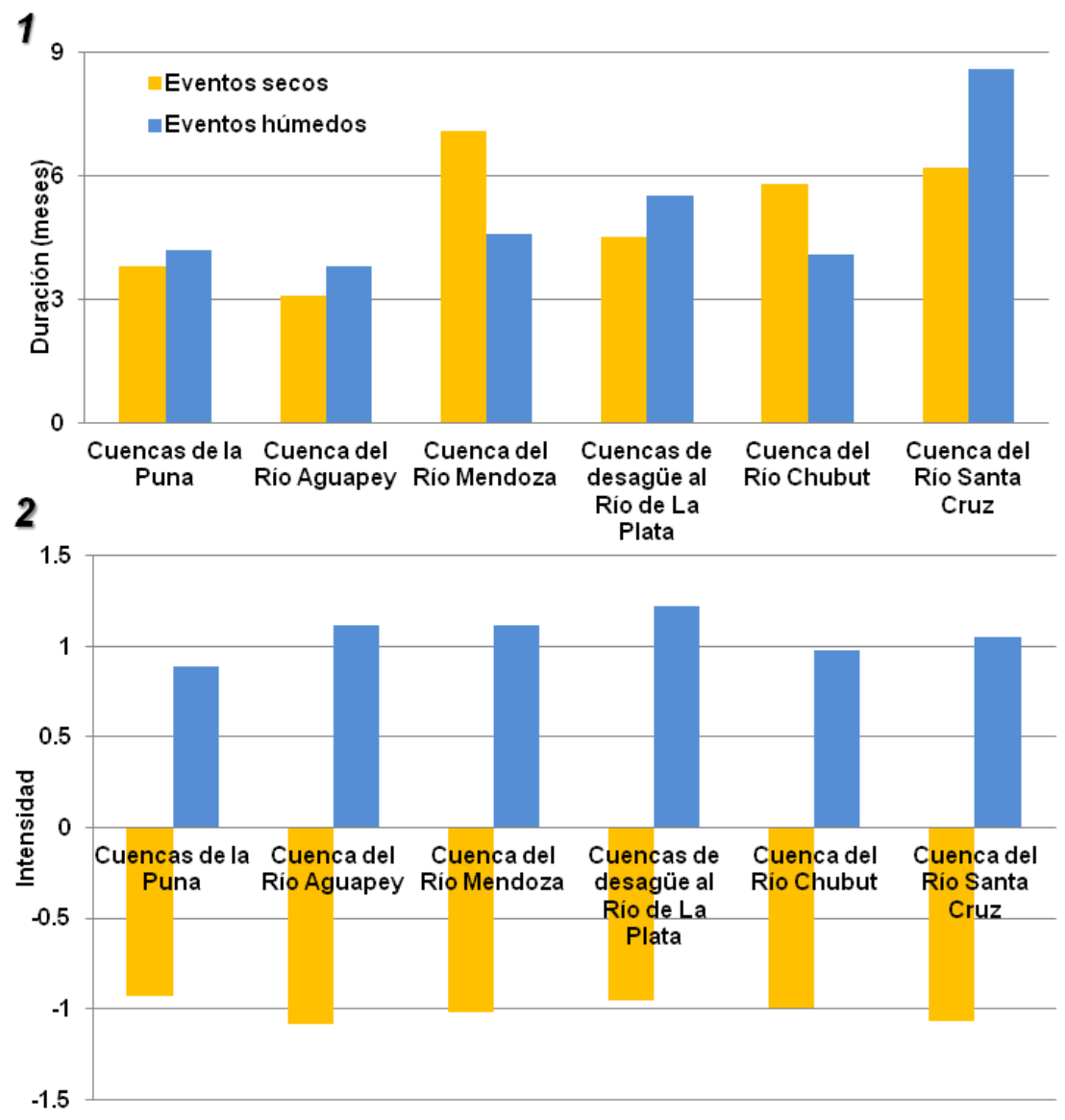

Fuente: elaboración propia, Ferrelli (2020).

\subsection{Variación espacio-temporal de las coberturas del suelo}

Una vez estudiadas las series de tiempo e identificada la variabilidad de los eventos secos, húmedos y normales, se estudiaron las variaciones de las coberturas del suelo para el período 1992-2018. A partir de ese momento, se identificaron los eventos más intensos para cada una de las cuencas Este período se consideró debido a la disponibilidad de los productos satelitales de la Agencia Espacial Europea que fue con los que se estudiaron las variaciones en todas las cuencas, dado que los mismos se encuentran validados a escala global y representan las condiciones de las coberturas en un año. Los eventos considerados se presentaron en la Tabla 2. Como es esperable debido a la localización en distintos climas, no todos los eventos se presentaron en forma simultánea en todas las cuencas estudiadas. Por tal motivo, se presentaron las situaciones observadas en cada cuenca (en sentido norte-sur) de forma separada identificando eventos Secos, Normales y Húmedos según su caracterización con el SPEI (Figura 2). Cabe destacar que durante el período de disponibilidad de datos satelitales (1992-2018), la cuenca del Río Mendoza no presentó un evento Húmedo, la serie se comportó principalmente negativa, predominando los eventos Secos o Normales (Figura 3). Por lo tanto, se seleccionó el evento normal de fase positiva más intensa que se originó en el período estudiado (Tabla 2). 
Tabla 2. Eventos secos, húmedos y normales en cuencas de Argentina seleccionados para estudiar la variación espacial de las coberturas del suelo. * No se evidenciaron eventos húmedos para la Cuenca del Río Mendoza durante el período 1992-2019. Se seleccionó el evento normal de fase positiva con mayor intensidad.

\begin{tabular}{|c|c|c|c|}
\hline Cuencas & Evento Seco & Evento Normal & Evento Húmedo \\
\hline Cuencas de la Puna & $2012($ SPEI -1,33) & 2007 (SPEI 0,41) & $2008($ SPEI 0,82) \\
\hline Cuenca del Río Aguapey & $2008($ SPEI -1,03) & $1999($ SPEI - 0,35) & $2002($ SPEI 1,72) \\
\hline Cuenca del Río Mendoza & $2012($ SPEI -1,54) & 2007 (SPEI -0,31) & $1999($ SPEI 0,44) \\
\hline $\begin{array}{c}\text { Cuenca de desagüe al Río de } \\
\text { La Plata }\end{array}$ & $2008($ SPEI -1,99) & 1999 (SPEI- 0,33) & $2002($ SPEI 1,64) \\
\hline Cuenca del Río Chubut & $2008($ SPEI -1,18) & $2012($ SPEI -0,09) & $2002($ SPEI 1,51) \\
\hline Cuenca del Río Santa Cruz & $1999($ SPEI -1,23) & $2012($ SPEI 0,004) & 2002 (SPEI 1,63) \\
\hline
\end{tabular}

Fuente: elaboración propia.

\subsubsection{Cuencas de la Puna}

Las coberturas del suelo predominantes de este espacio corresponden a los suelos descubiertos (>60\%) y a los matorrales (> 25\%). Sin embargo, se observaron también cobertura vegetal correspondientes a vegetación nativa, cobertura de herbáceas, cuerpos de agua, salinas y pastizales destinados al pastoreo (Figura 5).

Figura 5. Distribución espacial y variación temporal de las coberturas del suelo de las Cuencas de la Puna durante distintos eventos pluviométricos.
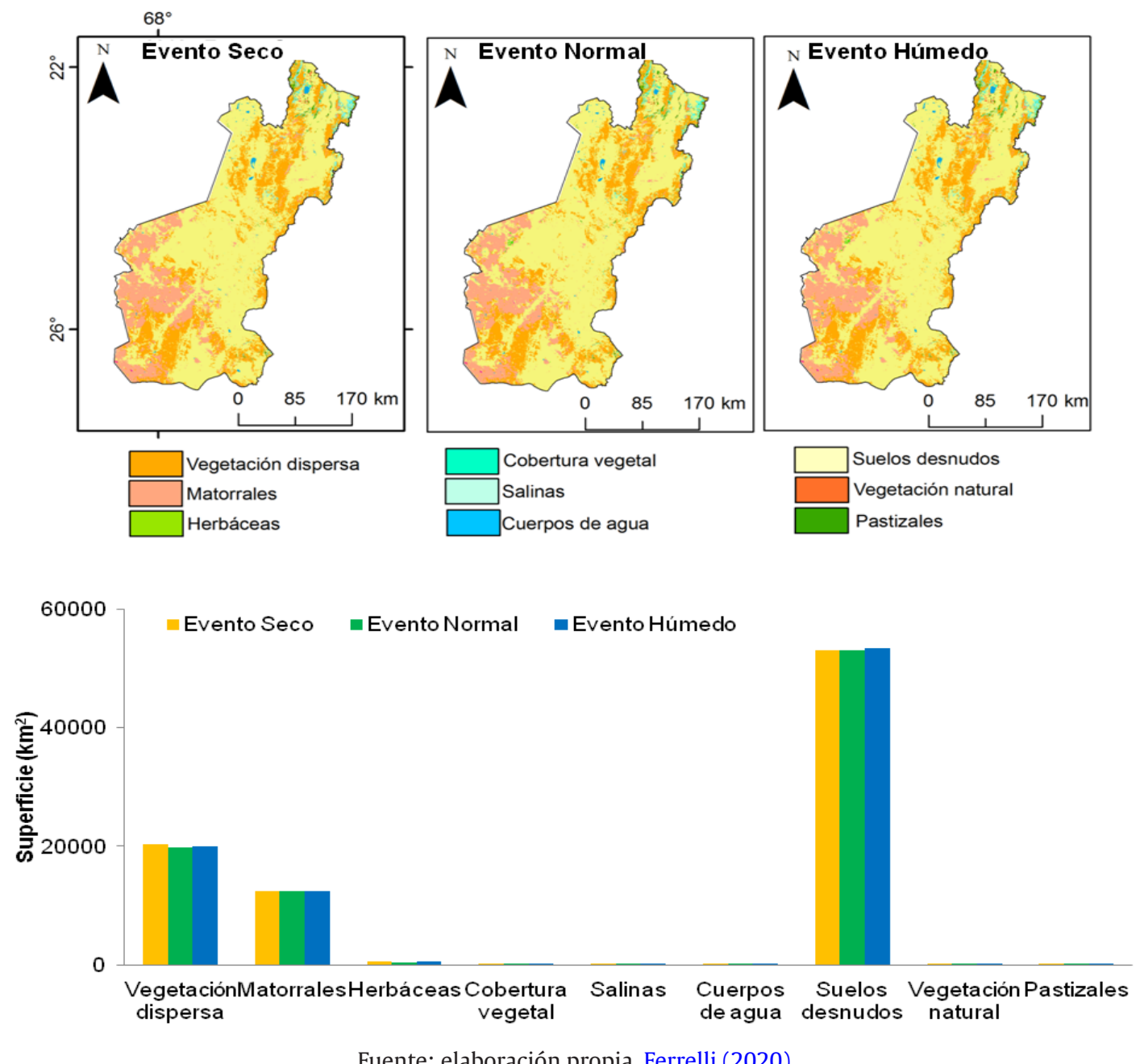

En las cuencas de La Puna, la vegetación dispersa disminuye su extensión en eventos normales y húmedos, respecto al seco (20.361,8 km en el evento seco, 19786,2 $\mathrm{km}^{2}$ en el normal y $18977 \mathrm{~km}^{2}$ en el húmedo). Esta cobertura presentó una correlación con los eventos climáticos $\left(R^{2} 0,71, P\right.$ 0,69, S 0,71 y $C$ $0,62)$. A pesar de ello, los matorrales no registraron una variación significativa $\left(R^{2}<0.05\right)$ y presentaron una 
superficie de $12445 \mathrm{~km}^{2}$. La cobertura que más se extiende en relación al aumento de la precipitación es la de pastizales, que pasa de 56,2 a $97,4 \mathrm{~km}^{2}$ entre en evento seco y uno húmedo. Su variación interanual presentó una significancia estadística dado que el $\mathrm{R}^{2}$ fue de 0,98 y el P y el $\mathrm{S}$ de 0.98 y 0.96 , respectivamente (Figura 5).

\subsubsection{Cuenca del Río Aguapey}

La cuenca del Río Aguapey presentó el evento seco más intenso de toda su serie en 2008, coincidente con la generación de un evento La Niña (según el índice ONI, propuesto por la NASA en su página web https://origin.cpc.ncep.noaa.gov/). Por otro lado, el evento Húmedo más intenso se originó en 2002, en coincidencia con un evento El Niño (Figura 6). En esta cuenca predominan los cultivos (> 27 \%) y las zonas inundables con herbáceas (> 32 \%). Al tratarse de un área con cultivos de secano y de clima subtropical, la variabilidad de las precipitaciones generó cambios notorios en la extensión de las coberturas entre los eventos, sobre todo en aquellas que dependen directamente de la precipitación como los cuerpos de agua, pastizales, cultivos, entre otras (Figura 6). Las variaciones de estas coberturas presentaron relación estadística entre su superficie (en $\mathrm{km} 2$ ) y el valor del SPEI anual, observando valores de R2 de 0,65, 0,61 y 0,58 para pastizales, cultivos y cuerpos de agua, respectivamente.

Por otro lado, se observó una marcada variación de los cultivos en relación a la ocurrencia de eventos secos, normales y húmedos. Se registraron 2163,7 km2, en el primero, 3111,9 km2 en el segundo y 3189,9 km2 en el último. Este aumento se observó en detrimento de otras coberturas. Por ejemplo, las zonas inundables + herbáceas se redujeron un $8 \%$ en el evento húmedo en relación con el seco (de 3136 a $2555 \mathrm{~km} 2$ ), al igual que la cobertura arbórea que pasó de $1175 \mathrm{~km} 2$ en el evento normal a $1045 \mathrm{~km} 2$ en el húmedo (Figura 6).

Figura 6. Distribución espacial y variación temporal de las coberturas del suelo de las Cuencas del Río Aguapey durante distintos eventos pluviométricos.

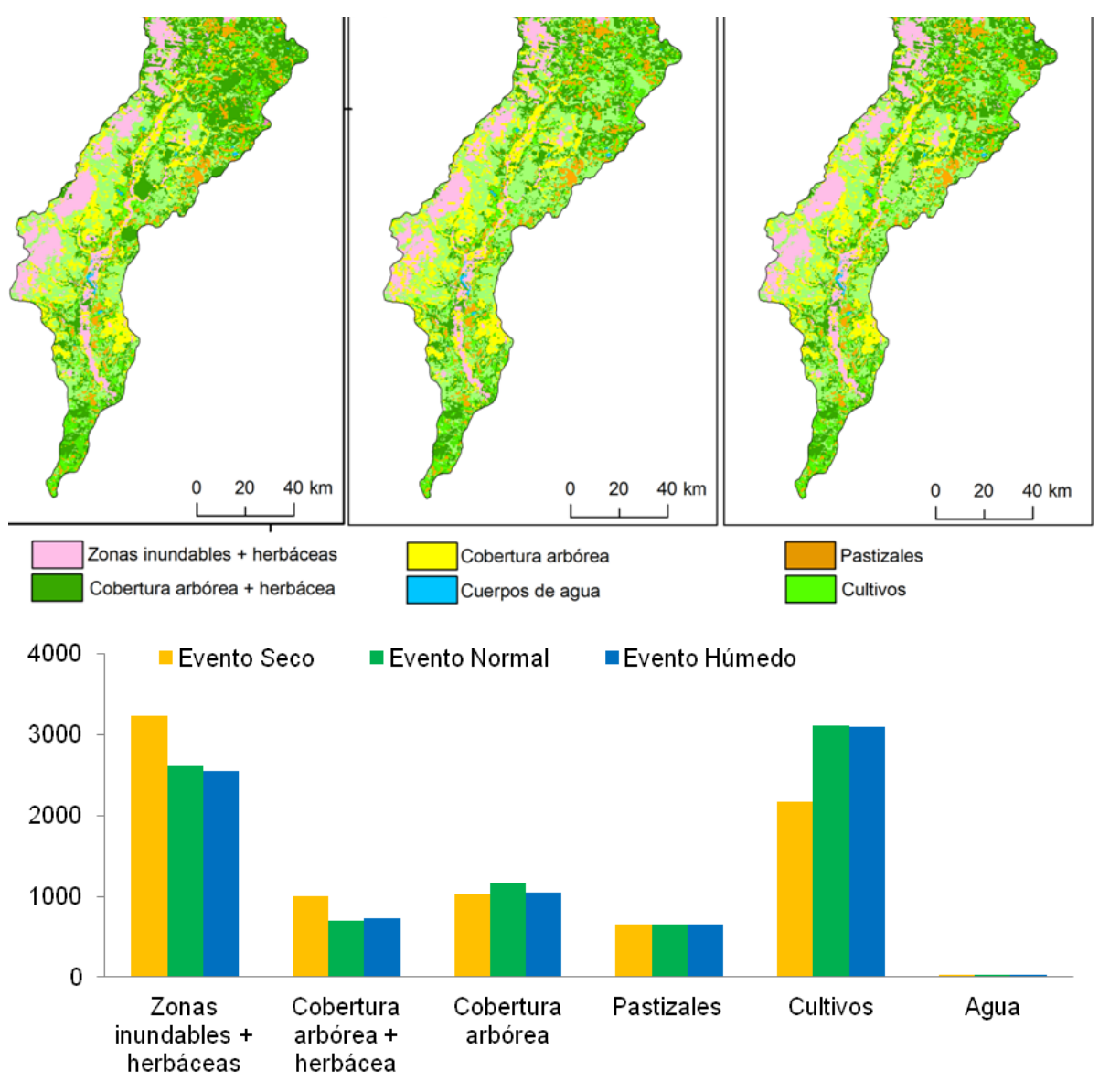

Fuente: elaboración propia, Ferrelli (2020).

\subsubsection{Cuenca del Río Mendoza}


La cuenca del Río Mendoza no tuvo una relación entre la generación de eventos de escala global como El Niño y La Niña con la sucesión de eventos secos o húmedos. Las coberturas del suelo con mayor predominancia fueron los matorrales ( $>60 \%$ ) y el suelo al descubierto ( $>31 \%$ ). Sin embargo, se observó una gran cantidad de cultivos bajo riesgo (>6\%) (Figura 7). Estas coberturas se mantuvieron en su mayoría estables durante los distintos eventos. La única que manifestó cambios significativos fue la de cultivos que registró un incremento de $200 \mathrm{~km}^{2}$ entre el evento seco y el húmedo (1255,9 y 1424,2 km², respectivamente) (Figura 7). La variación interanual de esta cobertura presentó un coeficiente de determinación $\mathrm{R}^{2}$ y de correlación (P y S) de 0,98, mientras que la concordancia fue de 0,95.

Figura 7. Distribución espacial y variación temporal de las coberturas del suelo de la Cuenca del Río Mendoza durante distintos eventos pluviométricos.
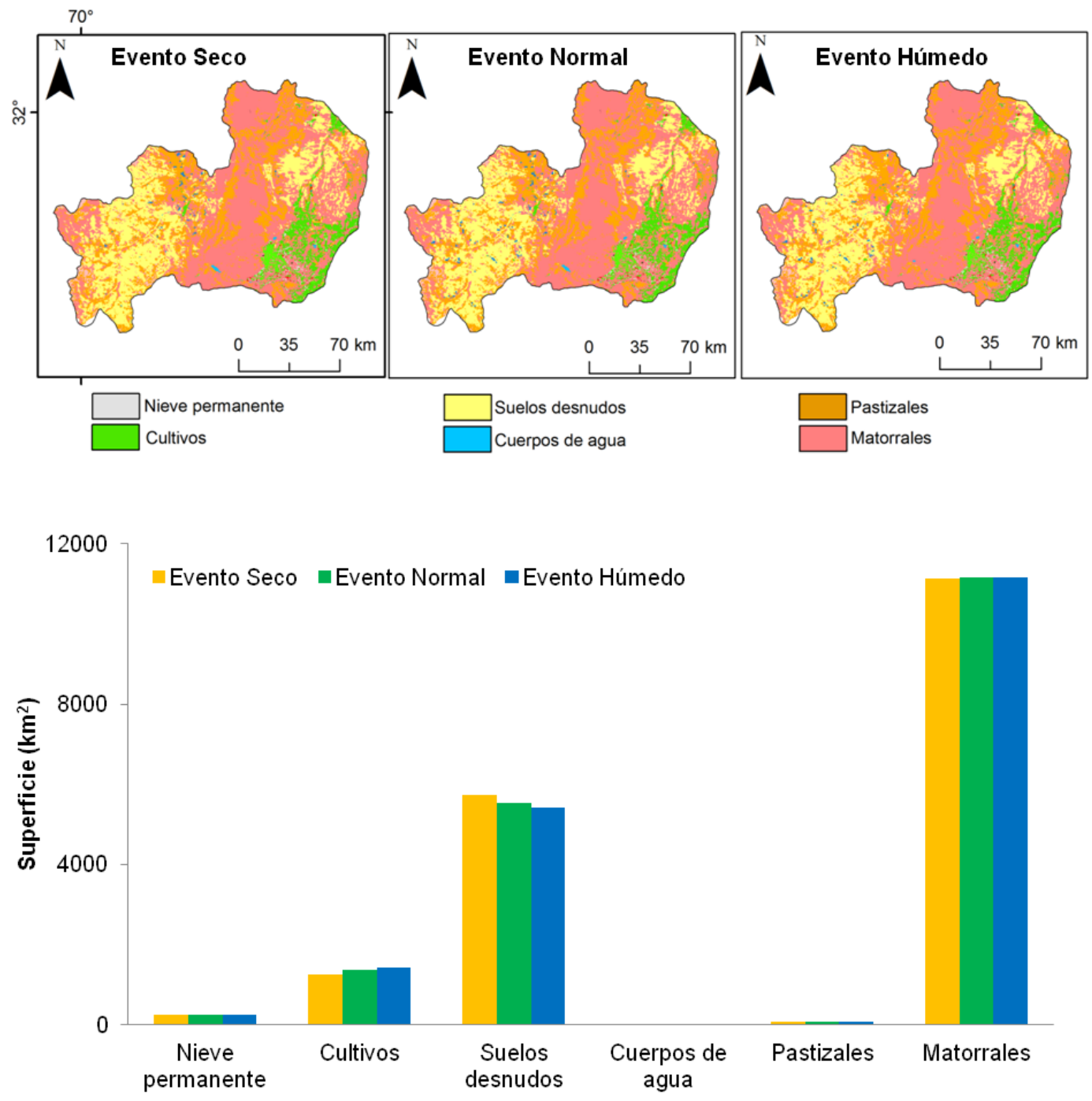

Fuente: elaboración propia, Ferrelli (2020).

\subsubsection{Cuencas de desagüe al Río de la Plata}

Las cuencas de desagüe al Río de La plata tuvieron la característica particular de presentar dentro

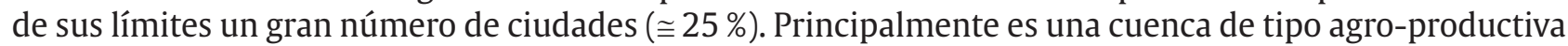
en donde las coberturas del suelo predominante fueron cultivos ( $>45 \%)$, pastizales ( $>15 \%)$ y vegetación natural (> 5\%) (Figura 8). En cuanto a los cultivos, se observó la misma tendencia que aquella identificada en la cuenca del Río Aguapey, los mismos tienden a extender su superficie en relación con los eventos más lluviosos. De esta manera, se registró un área de 4978,6 km2 durante el evento seco y se extendió a 5869 $\mathrm{km}^{2}$ durante el evento húmedo. Estas variaciones interanuales tuvieron una correlación estadísticamente significativa entre la superficie de la cobertura y la variación interanual del SPEI. De esta manera, se observaron valores de $\mathrm{R}^{2}$ de 0,78 , mientras que los índices P y S fueron de 0,75 y 0,74 , respectivamente. El incremento de los cultivos tuvo una relación directa con el decrecimiento de las áreas de pastizal, dado que 
las mismas registraron $2467 \mathrm{~km}^{2}$ en un evento húmedo y 2760,9 km² en el seco (Figura 8).

Figura 8. Distribución espacial y variación temporal de las coberturas del suelo de las cuencas de desagüe al Río de La Plata durante distintos eventos pluviométricos.
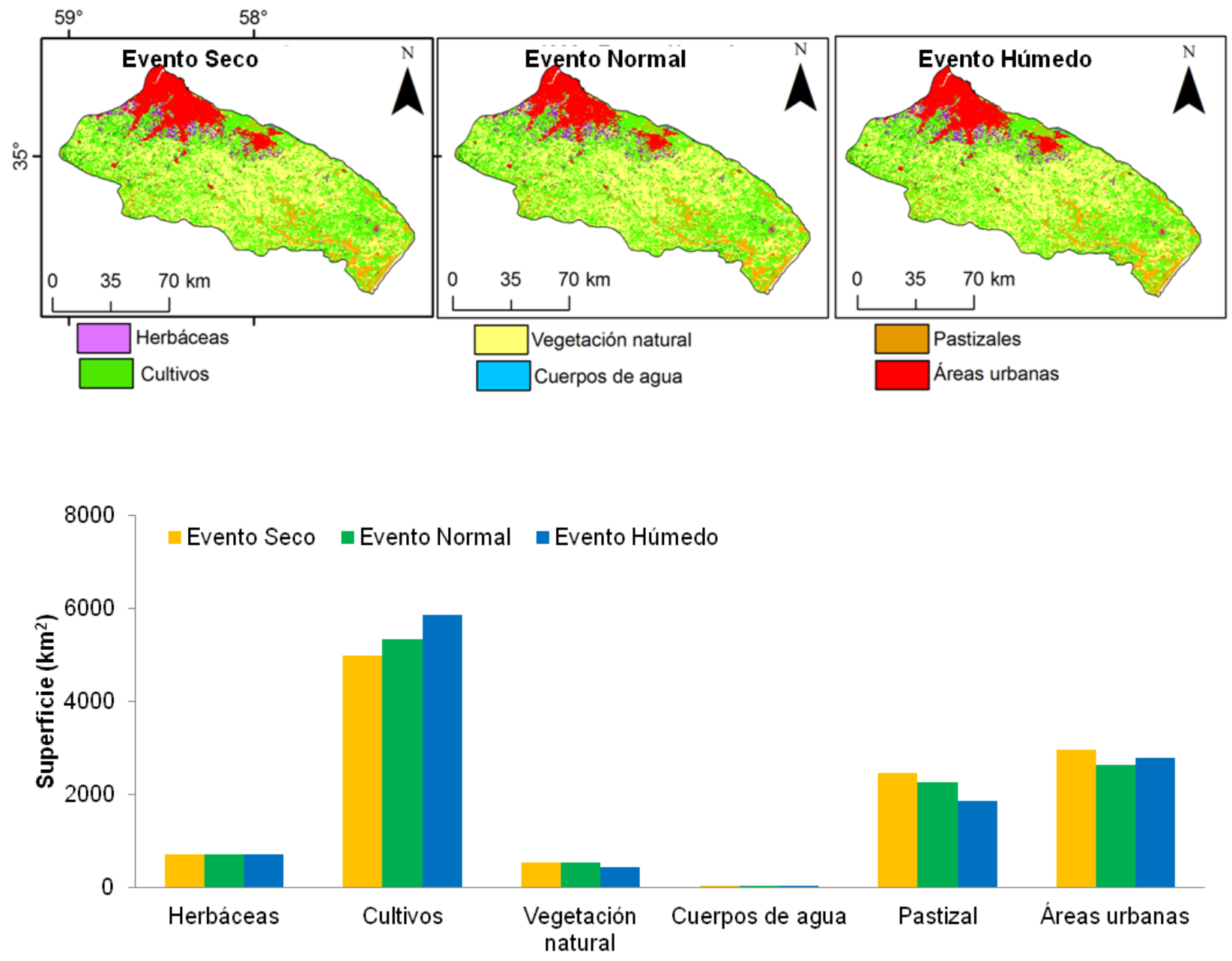

Fuente: elaboración propia, Ferrelli (2020).

\subsubsection{Cuencia del Río Chubut}

La cuenca del Río Chubut se caracterizó por presentar una predominancia de la vegetación dispersa y los matorrales ( $>42 \mathrm{y}>50 \%$, respectivamente) aunque también se observaron cultivos sobre el este

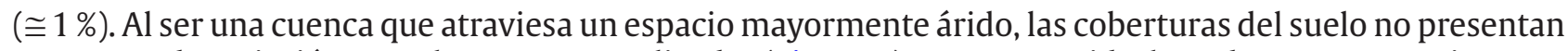
una marcada variación entre los eventos analizados (Figura 9). En este sentido, las coberturas no registraron modificaciones en la superficie de las dos coberturas más extensas (vegetación dispersa $\cong 22937 \mathrm{~km}^{2} \mathrm{y}$ matorrales $\cong 27242 \mathrm{~km}^{2}$ ). Ninguna de estas identificaron valores de $\mathrm{R}^{2}$, P, S y C significativos $(<0,05)$. Sin embargo, se presentaron pequeñas variaciones en los cultivos $\left(502,2 \mathrm{~km}^{2}\right.$ en un evento seco y $553 \mathrm{~km}^{2}$ en un evento húmedo), en los cuerpos de agua (de 103 a $115 \mathrm{~km}^{2}$ ) y en los suelos desnudos (582,9 a $548 \mathrm{~km}^{2}$ ) (Figura 9). Estas últimas tuvieron valores de $\mathrm{R}^{2}$ de $0,81,0,76$ y 0,55 , respetivamente.

Figura 9. Distribución espacial y variación temporal de las coberturas del suelo de la Cuenca del Río Chubut durante distintos eventos pluviométricos. 

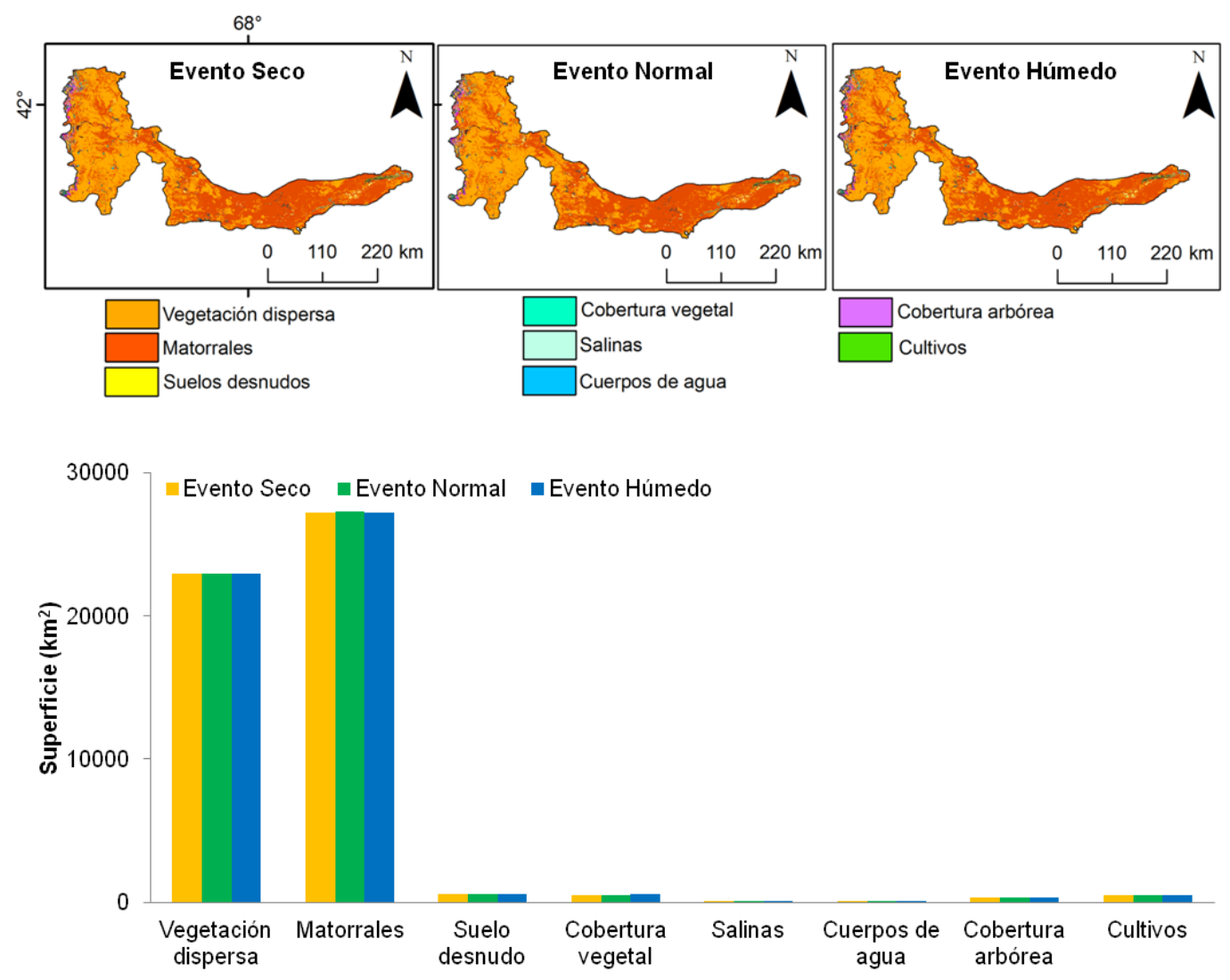

Fuente: elaboración propia, Ferrelli (2020).

\subsubsection{Cuenca del Río Santa Cruz}

Finalmente, la cuenca del Río Santa Cruz tiene sus nacientes en la Cordillera de los Andes, en donde se identificó la presencia de nieve permanente y cuerpos de agua. Hacia el este se observó la presencia de vegetación dispersa, matorrales y en menor medida cobertura arbórea (Figura 10). Las coberturas no presentaron variaciones significativas en aquellas de mayor superficie $\left(R^{2}, P, S\right.$ y $C$ menores a 0,05$)$. Estas

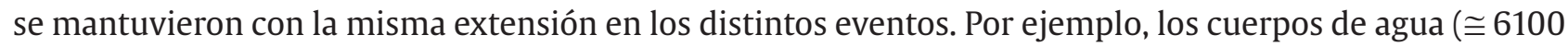
$\left.\mathrm{km}^{2}\right)$, la vegetación dispersa $\left(\cong 2632 \mathrm{~km}^{2}\right.$ ). La cobertura que tuvo fluctuaciones entre los distintos eventos fue la de pastizales. La misma pasó de 1083,1 en el evento seco a 1256,9 $\mathrm{km}^{2}$ en el evento húmedo (Figura 10). A pesar de ello, al analizar su comportamiento interanual, no registró valores estadísticos destacables $\left(R^{2}=0,21\right.$, P y $S=0,18$ y $\left.C=0,08\right)$

Figura 10. Distribución espacial y variación temporal de las coberturas del suelo de la Cuenca del Río Santa Cruz durante distintos eventos pluviométricos. 

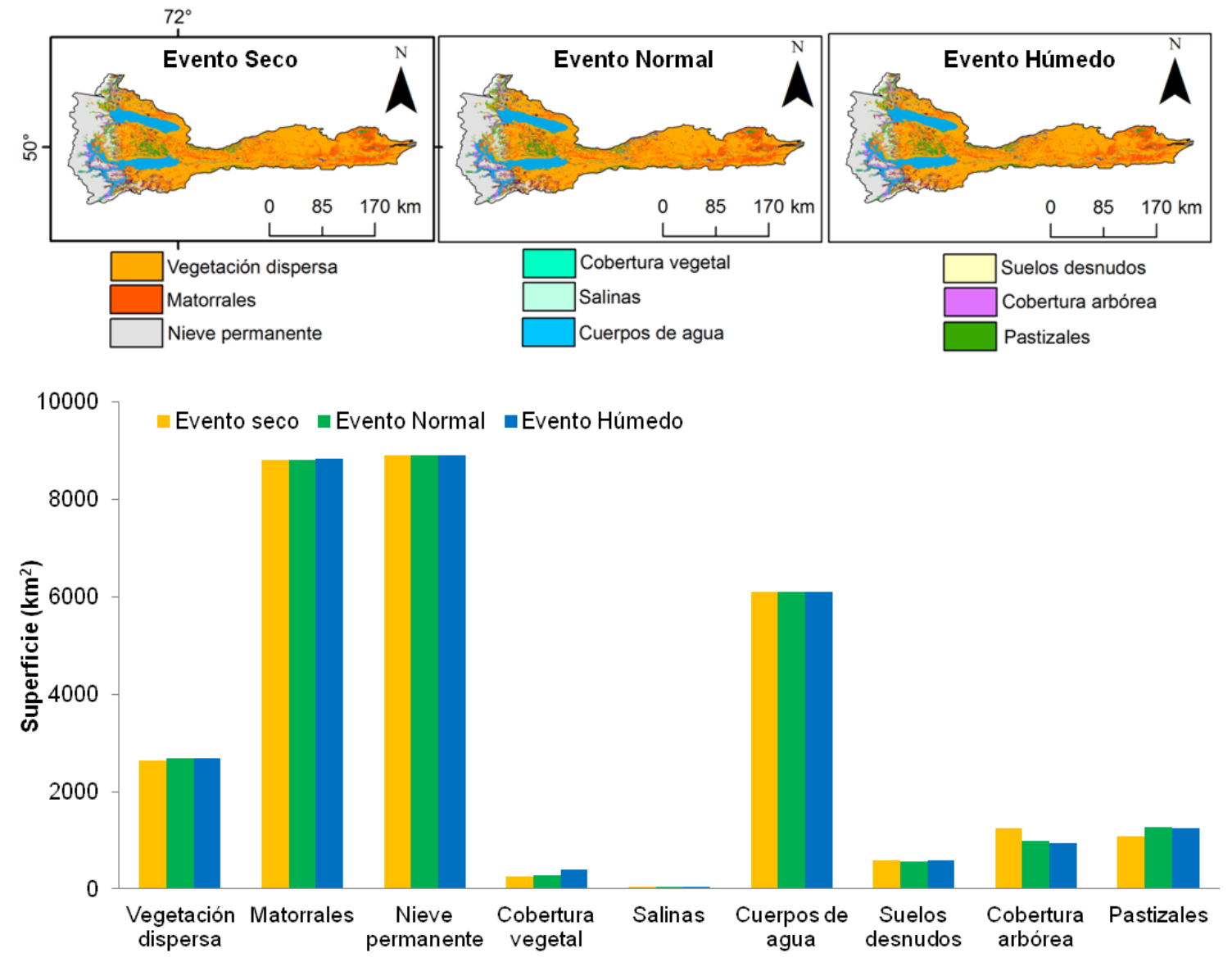

Fuente: elaboración propia, Ferrelli (2020).

\section{Discusión}

La variabilidad climática observada en distintos sectores de Argentina presentó algunos aspectos a destacar. Por un lado, exceptuando el caso de las cuencas de La Puna y del Río Mendoza, los eventos con mayor intensidad identificados luego del año 2000 se originaron en simultáneo en todas las cuencas. Esta condición podría estar relacionada con la generación del fenómeno El Niño Oscilación Sur. Además, las diferencias encontradas en la duración y la frecuencia de los eventos tanto secos como húmedos podrían mantener una linealidad con el Índice de Oscilación del Sur. Existe evidencia de que, en gran parte del país, los eventos secos y húmedos mantienen relación con la oscilación de ciertos índices como lo son el Índice Oceánico de El Niño, la Oscilación del Atlántico y la Oscilación del Sur (Bohn et al., 2016; Aliaga et al., 2017; Scordo et al., 2018; Ferrelli et al., 2019).

Es destacable que a partir de la década del 2000 se registraron cambios significativos en la distribución interanual de los períodos secos y húmedos. Esta situación fue más evidente en la cueca del Río Mendoza y en las cuencas de La Puna, en donde a partir de ese año no se evidenciaron eventos húmedos. Se ha demostrado en otras investigaciones que en gran parte del país, a partir de la década del 2000, se identificaron cambios estructurales altamente significativos en las series de tiempo que permiten afirmar la existencia de una tendencia hacia el calentamiento y hacia el aumento de la torrencialidad de las precipitaciones (Chen et al., 2017; Ferrelli et al., 2019). Esto ocasiona que las variaciones termopluviométricas se generen con mayor intensidad, afectando no sólo al ambiente, sino también a las actividades económicas que realiza la población, principalmente los cultivos de secano y la ganadería extensiva (Brendel et al., 2017).

Los cultivos y los pastizales correspondieron a las áreas más vulnerables a la variación de los eventos secos y húmedos. Se ha evidenciado que a escala nacional los eventos de heladas meteorológicas tienen una tendencia negativa, como consecuencia de un aumento de las temperaturas máximas (Barrucand y Rusticucci, 2001; Fernández-Long et al., 2013). Además, las precipitaciones del país, al igual que en el resto del mundo, tienen una distribución espacial heterogénea, caracterizada en su mayoría por un cambio en su intensidad y torrencialidad (Qamar et al., 2017). 
El conocimiento de la variabilidad de las precipitaciones en distintas cuencas de Argentina está estrechamente vinculado con las actividades económicas que se realizan en el país. Las fluctuaciones pluviométricas y de la evapotranspiración podrían aumentar el riesgo de pérdida de cosechas, lo que desencadenaría en un consecuente impacto negativo en las economías locales (Ferrelli, 2019). Es destacable que, en aquellas áreas caracterizadas por la rotación de cultivos, la variación de la precipitación podría afectar su normal desarrollo (Monzón et al., 2007; Brendel et al., 2019).

Por otro lado, las pérdidas ocasionadas por la variabilidad de las precipitaciones no serán iguales para cada cuenca estudiada, dado que las mismas se localizan en distintos climas y tienen distintas características geomorfológicas. A pesar de ello, la información sobre la ocurrencia y periodicidad de eventos secos y húmedos podría favorecer a estimar un período óptimo para el crecimiento de los cultivos y los pastizales destinados a las actividades agropecuarias, con el fin de reducir las pérdidas y daños que podrían producirse durante el período de siembra (Menzel et al., 2003; Grassini et al., 2011; FernandezLong et al., 2013; Worku et al., 2019).

Se destaca que la información obtenida en este estudio podría favorecer a las actividades turísticas, agropecuarias, al control de inundaciones, a la disponibilidad de agua superficial, a realizar manejos y gestiones sobre el territorio, entre otras (Ferrelli, 2017; Worku et al., 2019). El análisis de la variabilidad climática determinado a escala de cuencas hidrográficas podría favorecer la gestión del territorio, dado que estas unidades espaciales son buenos estimadores de los cambios ambientales a partir de las modificaciones que se observan en su paisaje (Williamson et al., 2009). Además, su delimitación favorece la implementación de planes de manejo del territorio a escala regional, con el objetivo de mejorar la calidad de vida de sus habitantes con vistas a un desarrollo sustentable (Funk et al., 2012).

Finalmente, es importante destacar que adquiere relevancia el estudio de la variabilidad de las precipitaciones desde el punto de vista del riesgo de inundaciones y sequías a los que está expuesto cada región de Argentina (Alemayehu y Bewkert, 2016), sobre todo en aquellas regiones en donde su economía está basada en cultivos de secano o en donde se emplazan gran cantidad de ciudades en las márgenes de los ríos. Por todo lo mencionado, el conocimiento de la variabilidad climática y sus efectos sobre las coberturas del suelo en las cuencas de Argentina debería ser considerado para lograr un eficaz manejo de los recursos naturales y aprovechamiento de sus servicios ecosistémicos, con la finalidad de conservar las actividades económicas (Zilio et al., 2017).

\section{Conclusiones}

Se realizó un estudio comparativo de la variabilidad climática y sus efectos sobre las coberturas del suelo en seis cuencas hidrográficas de Argentina. Las mismas estuvieron localizadas en distintas zonas climáticas. Se destaca en este contexto que la cuenca del Río Mendoza no presentó evidencia de eventos húmedos luego del año 1985 y, en contraposición, no registró eventos secos durante el período 19541984. Las cuencas de La Puna no presentaron períodos extremos durante el período 1951-2019. La mayor ocurrencia de eventos secos y húmedos se registraron en los climas subtropicales (cuenca del Río Aguapey) y templados húmedos (cuenca de desagüe al Río de La Plata).

Se observaron períodos de sequía que se dieron en simultáneo en la mayor parte del país. Los mismos coincidieron con la ocurrencia de eventos La Niña. La misma situación se evidenció con los eventos húmedos, coincidentes con eventos El Niño. Se destaca que, en todos los casos analizados, las coberturas del suelo presentaron una variación en relación con las fluctuaciones del SPEI. Las coberturas que más se vieron afectadas fueron los cultivos y los pastizales, aunque también se evidenciaron cambios en los cuerpos de agua.

En lo que respecta a las coberturas del suelo se destaca que las cuencas de La Puna se caracterizaron por presentar eventos húmedos y normales en períodos diferentes al resto de las cuencas. El evento El Niño registrado en 2002 tuvo efectos sobre las coberturas del suelo de las cuencas de desagüe del Río de La Plata, en la del Río Chubut y en la del Río Santa Cruz. Se observó que en las cuencas de clima subtropical y templado, la superficie de la mayor parte de las coberturas del suelo identificadas tuvieron una relación estadística con la variación interanual del SPEI.

Del estudio realizado, se destaca que el conocimiento de la variabilidad climática y sus efectos sobre las coberturas del suelo en distintas cuencas de Argentina genera la necesidad de realizar planes de ordenamiento del territorio que considere sus condiciones de sitio, las características climáticas predominantes y las variaciones y efectos de la ocurrencia de eventos secos y húmedos sobre las actividades económicas que la población realiza. Por lo tanto, la información presentada en este trabajo conforma una base de datos esencial que podría servir de base para orientar políticas destinadas a mejorar la calidad de 
vida de la población y el ambiente.

\section{Referencias Bibliográficas}

Adrian, R., O’Reilly, C. M., Zagarese, H., Baines, S. B., Hessen, D. O., Keller, W., ... \& Weyhenmeyer, G. A. (2009). Lakes as sentinels of climate change. Limnology and oceanography, 54(6part2), 2283-2297. Alemayehu, A. \& Bewket, W. 2016. Local climate variability and crop production in the central highlands of Ethiopia. Environmental Development, 19: 36-48.

Aliaga, V.S., Ferrelli, F., \& Piccolo, M. C. (2017). Regionalization of climate over the Argentine Pampas. International journal of climatology, 37, 1237-1247. doi: https://doi.org/10.1002/joc.5079

Aliaga, V. S., Ferrelli, F., Alberdi-Algarañaz, E. D., Bohn, V. Y., \& Piccolo, M. C. (2016). Distribution and variability of precipitation in the Pampas, Argentina. Cuadernos de investigación Geográfica, 42(1), 261-280. doi: $10.18172 /$ cig.2867

Barrucand, M., \& Rusticucci, M. (2001). Climatología de temperaturas extremas en la Argentina. Variabilidad temporal y regional. Meteorológica, 26(1-2), 85-102.

Beck, H. E., Zimmermann, N. E., McVicar, T. R., Vergopolan, N., Berg, A., \& Wood, E. F. (2018). Present and future Köppen-Geiger climate classification maps at 1-km resolution. Scientific data, 5, 180214. doi: 10.1038/sdata.2018.214

Bohn, V. Y., Delgado, A. L., Piccolo, M. C., \& Perillo, G. M. (2016). Assessment of climate variability and land use effect on shallow lakes in temperate plains of Argentina. Environmental Earth Sciences, 75(9), 818. doi: https://doi.org/10.1007/s12665-016-5569-6

Brendel, A. S., Bohn, V. Y., \& Piccolo, M. C. (2017). Variabilidad de la precipitación y su relación con los rendimientos agrícolas en una región semiárida de la llanura pampeana (Argentina). Estudios Geográficos, 78(282), 7-29. doi: https://doi.org/10.3989/estgeogr.201701

Brendel, A. S., Ferrelli, F., Piccolo, M. C., \& Perillo, G. M. (2019). Assessment of the effectiveness of supervised and unsupervised methods: maximizing land-cover classification accuracy with spectral indices data. Journal of Applied Remote Sensing, 13(1), 014503. doi:10.1117/1.JRS.13.014503

Chen, A., He, X., Guan, H., \& Cai, Y. (2018). Trends and periodicity of daily temperature and precipitation extremes during 1960-2013 in Hunan Province, central south China. Theoretical and applied climatology, 132(1-2), 71-88. doi: https://doi.org/10.1007/s00704-017-2069-x

ESA. Land Cover CCI Product User Guide Version 2. Tech. Rep. (2017). Recuperado de:maps.elie.ucl. ac.be/CCI/viewer/download/ESACCI-LC-Ph2-PUGv2_2.0.pdf

Fernández-Long, M. E., Müller, G. V., Beltrán-Przekurat, A., \& Scarpati, O. E. (2013). Long-term and recent changes in temperature-based agroclimatic indices in Argentina. International Journal of Climatology, 33(7), 1673-1686. doi: https://doi.org/10.1002/joc.3541

Ferrelli, Federico (2017). Variabilidad pluviométrica y sus efectos sobre las coberturas del suelo al sur de la provincia de Buenos Aires, Argentina. Revista Geográfica Venezolana, 58(1),26-37. ISSN: 1012-1617. Recuperado de: https://www.redalyc.org/articulo.oa?id=3477/347753792003

Ferrelli, F. (2019). Evaluación de eventos termo-pluviométricos diarios en una región semiárida de Argentina. Revista Universitaria de Geografía, 28(2), 87-107. ISSN 1852-4265. Recuperado de: http:// bibliotecadigital.uns.edu.ar/scielo.php?script=sci_arttext\&pid=S1852-42652019002200005\&lng=pt\&nrm $=$ iso

Ferrelli, F., Brendel, A. S., Aliaga, V. S., Piccolo, M. C., \& Perillo, G. M. E. (2019). Climate regionalization and trends based on daily temperature and precipitation extremes in the south of the Pampas (Argentina). Cuadernos de Investigación Geográfica, 45(1), 393-416. doi: http://doi.org/10.18172/cig.3707

Ferrelli, F., Bustos, M. L., Cisneros, H., \& Piccolo, M. C. (2015). Utilización de imágenes satelitales para el estudio de la distribución térmica en distintas coberturas del suelo de la ciudad de Bahía Blanca (Argentina). Revista de Teledetección. Asociación Española de Teledetección. doi: http://dx.doi.org/10.4995/ $\underline{\text { raet.2015.4018 }}$

Funk, C., Rowland, J., Eilerts, G., Kebebe, E., Biru, N., White, L., \& Galu, G. (2012). A climate trend analysis of Ethiopia. US Geological Survey, Fact Sheet, 3053(5), 6. doi: 10.3133/fs20123053

Gordon, L. J., Peterson, G. D., \& Bennett, E. M. (2008). Agricultural modifications of hydrological 
flows create ecological surprises. Trends in ecology E' evolution, 23(4), 211-219. doi: https://doi.org/10.1016/j. tree.2007.11.011

Grassini, P., Thorburn, J., Burr, C., \& Cassman, K. G. (2011). High-yield irrigated maize in the Western US Corn Belt: I. On-farm yield, yield potential, and impact of agronomic practices. Field crops research, 120(1), 142-150. doi: https://doi.org/10.1016/j.fcr.2010.09.012

Houghton, R. A. (1993). Is carbon accumulating in the northern temperate zone?. Global Biogeochemical Cycles, 7(3), 611-617. doi: https://doi.org/10.1029/93GB01163

Köppen, W. \& Geiger, R., (1936). Das geographische System der Klimate. Berlín, Alemania: Verlag von Gebrüder Borntraeger.

Köppen, W., (1918). Klassifikation der Klimate nach Temperatur, Niederschlag und Jahresablauf. Petermanns Geogr. Mitt., 64, 193-203, 243-248.

Lehner, B., Döll, P., Alcamo, J., Henrichs, T., \& Kaspar, F. (2006). Estimating the impact of global change on flood and drought risks in Europe: a continental, integrated analysis. Climatic Change, 75(3), 273-299. doi: https://doi.org/10.1007/s10584-006-6338-4

Menzel, A., Jakobi, G., Ahas, R., Scheifinger, H., \& Estrella, N. (2003). Variations of the climatological growing season (1951-2000) in Germany compared with other countries. International Journal of Climatology: A Journal of the Royal Meteorological Society, 23(7), 793-812. doi: https://doi.org/10.1002/ joc.915

Monzón, J. P., Sadras, V. O., Abbate, P. A., \& Caviglia, O. P. (2007). Modelling management strategies for wheat-soybean double crops in the south-eastern Pampas. Field Crops Research, 101(1), 44-52. doi: https://doi.org/10.1016/i.fcr.2006.09.007

Nosetto, M. D., Jobbágy, E. G., \& Paruelo, J. M. (2005). Land-use change and water losses: the case of grassland afforestation across a soil textural gradient in central Argentina. Global Change Biology, 11(7), 1101-1117. doi: https://doi.org/10.1111/j.1365-2486.2005.00975.x

Qamar, M. U., Azmat, M., Shahid, M. A., Ganora, D., Ahmad, S., Cheema, M. J. M., ... \& Khan, M. I. (2017). Rainfall extremes: a novel modeling approach for regionalization. Water resources management, 31(6), 1975-1994. doi: https://doi.org/10.1007/s11269-017-1626-5

Scordo, F., Perillo, G. M., \& Piccolo, M. C. (2018). Effect of southern climate modes and variations in river discharge on lake surface area in Patagonia. Inland Waters, 8(3), 341-355. doi:10.1080/20442041.201 $\underline{8.1487118}$

Taboada, M. A., Damiano, F., \& Micucci, F. G. (2012). Aspectos físicos que condicionan la disponibilidad de agua para los cultivos. Facultad de Agronomía, UBA. Buenos Aires, p. 133-167.

Vicente-Serrano, S. M., Beguería, S., \& López-Moreno, J. I. (2010). A multiscalar drought index sensitive to global warming: the standardized precipitation evapotranspiration index. Journal of climate, 23(7), 1696-1718. doi: https://doi.org/10.1175/2009JCLI2909.1

Williamson, C. E., Saros, J. E., Vincent, W. F., \& Smol, J. P. (2009). Lakes and reservoirs as sentinels, integrators, and regulators of climate change. Limnology and Oceanography, 54(6part2), 2273-2282. doi: https://doi.org/10.4319/lo.2009.54.6_part_2.2273

Worku, G., Teferi, E., Bantider, A., \& Dile, Y. T. (2019). Observed changes in extremes of daily rainfall and temperature in Jemma Sub-Basin, Upper Blue Nile Basin, Ethiopia. Theoretical and Applied Climatology, 135(3-4), 839-854. doi: https://doi.org/10.1007/s00704-018-2412-X

Zilio, M. I., Alfonso, M. B., Ferrelli, F., Perillo, G. M., \& Piccolo, M. C. (2017). Ecosystem services provision, tourism and climate variability in shallow lakes: The case of La Salada, Buenos Aires, Argentina. Tourism Management, 62, 208-217. doi: https://doi.org/10.1016/j.tourman.2017.04.008 